\title{
Paroxetine Increased the Serum Estrogen in Postmenopausal Women with Depressive and Anxiety Symptoms
}

\author{
Borong Zhou*\#, Shuangyan Xie\#, Jiajia Hu\#, Xiaofang Sun, Haitao Guan, Yanhua Deng \\ Department of Neurology, Key Laboratory of Reproduction and Genetics of Guangdong Higher Education \\ Institutes, The Third Affiliated Hospital of Guangzhou Medical University, Guangzhou, China \\ Email: zhoubr8@aliyun.com
}

Received 5 September 2014; revised 4 October 2014; accepted 8 November 2014

Copyright (C) 2014 by authors and Scientific Research Publishing Inc.

This work is licensed under the Creative Commons Attribution International License (CC BY). http://creativecommons.org/licenses/by/4.0/

\section{Abstract}

Objective: Both of selective serotonin reuptake inhibitors (SSRIs) and estrogen can modulate emotion and cognition function in post-menopause women, moreover SSRIs can influence estrogen system in rats and aquatic wildlife but most of them for reproductive ability. The aim of this study was to investigate the possible relationship between SSRI, estrogen, and emotion and cognition in post-menopause women with anxiety and depressive symptoms .Methods: A double-blind, randomized controlled trials of Paroxetine, an SSRI $(n=44)$, versus placebo $(n=38)$ for 6 months in post-menopausal women with anxiety and depressive symptoms. For screening anxiety, depression and mild cognitive impairment (MCI), we use the Hamilton Anxiety Rating Scale (HAM-A), the Hamilton Depression Rating Scale (HAM-D) and the Chinese Version of the Montreal cognitive assessment (MoCA-CV). And sex hormones were measured by ELASE method which is serum estradiol (E2), follicle stimulating hormone (FSH) and luteinizing hormone (LH). Results: Paroxetine increased serum E2 and decreased LH, FSH significantly $(P<0.05)$. Meanwhile, HAM-A and HAM-D scores declined and MoCA-CV score raised by Paroxetine $(P<0.05)$. We also found that a negative association between $\mathrm{E} 2$ and scores of HAM-A and HAM-D at pre-treatment and post-treatment of Paroxetine (HAM-A: $R=-0.27, R=-0.24$; HAM-D: $R=-0.65, R=-0.37$ ), while a positive correlation between E2 and MoCA-CV scores $(R=0.52, R=0.47)$. Conclusions: This founding suggests that SSRI can increase serum estrogen levels and the change of estrogen may be one of mechanism in SSRI's improve emotion and cognitive function in post-menopausal women.

\section{Keywords}

Paroxetine, Estrogen, Anxiety or Depressive Symptom, Cognition, Post-Menopausal Women

\footnotetext{
${ }^{*}$ Corresponding author.

\#All authors made substantial contributions to the study and this manuscript. None was compensated for manuscript preparation.
} 


\section{Introduction}

Mood disorder, especially depression, and dementia are commonly in comorbidity occurring in the aged population (Korczyn et al., 2009). Moreover, both of the diseases affect much more women than men (Korczyn et al., 2009). Many literatures have reported that, a hypoestrogenic state, such as premenstrual, postpartum, menopausal period, has been proposed to negatively affect emotional stability and cognitive function, especially in post-menopausal women (Shumaker et al. 2003). In the post-menopausal period, 18\% of women had at least one psychiatric disorder with depression being the most common (16\%) followed by general anxiety or panic (6\%) and alcohol abuse (1\%) (Colenda et al. 2010). Furthermore, the frequency of a psychiatric disorder is associated with poorer cognitive functioning among older women (Colenda et al. 2010). It also supported by another study which reported that the percent of women aged 48 to 50 suffering cognition disorder increase to $40 \%$ (Amyaloysi et al., 2006) (menopausal average age is 51). Thus, the hypoestrogenic state may be an important factor causing affective and cognitive disorder in post-menopausal women.

In consequence, several studies have analyzed that the role of estrogen in modulation of depression and cognitive impairment in elder women. First, estrogen produces antidepressant-like actions by themselves and facilitate the clinically used antidepressant (Estrada-Camarena et al., 2010) and in post-menopausal women (Zanardi et al., 2007). Second, randomized control trials, while clearly not entirely consistent, nevertheless have shown that performance on $47 \%$ of memory measures was better in postmenopausal women who received estrogen replacement therapy (ERT) (Zec et al., 2002). In another observational study reported by Tang et al., ERT was also associated with significantly reduced risk for Alzheimer disease (AD) in a sample of 1124 women enrolled in the Manhattan Study of Aging (Tang et al., 1996). Thus, a reduced risk of AD, improve cognitive functioning and depressive symptoms are found in postmenopausal women who use 17 $\beta$-estradiol.

Overall, hypoestrogenic state resulting in affective and cognitive disorder while ERT improving depression and cognitive impairment suggest that estrogen play an important role in modulating affection and cognition in postmenopausal women.

Though estrogen have shown a positive effect, current guidelines do not recommend hormone therapy to improve depression and cognitive disorder not only because of no consistent association (Potyk, 2005) between estrogen therapy and cognitive function but also because HRT's disadvantages emerged from the large randomized controlled trial— the Women health initiative (WHI) — that found no benefit for prevention for cardiovascular diseases (Writing Group for the WHI Investigators, 2002) and, particularly, an increase in breast cancer incidence associated with hormone replacement therapy (HRT) (Million Women Study Collaborators, 2003). Thus, in last few years, interest in nonhormonal alternatives for treatment of depressive symptom in post-menopausal women has increased, in particular, the use of SSRI for treatment of mood disorders.

SSRIs has become favored treatment for female patients with depression, especially in late-life women with cognitive impairment. First, SSRIs are more effective and result in fewer adverse drug reactions in women than other antidepressions such as tricyclic antidepressants (TCAs) (Uher et al., 2009a). Second, in SSRIs treatment, women show a superior response to SSRIs comparing with men (Trivedi et al., 2006). In retrospective analysis of 235 men and 400 women randomly assigned to receive the SSRI sertraline or the TCA imipramine, women responded preferentially to Sertraline and men show a better response to imipramine (Kornstein et al., 2000). Third, in post-menopausal depressive women with mild cognitive impairment (MCI), SSRI, Paroxtine, treatment has been reported to improve performance in cognitive tasks and increase serum level of brain derived neurotrophic factor (BDNF) (Cubeddu et al., 2010; Wroolie et al., 2006; Fales et al. 2009). However, little is known what mechanism in gender preference of SSRIs in female.

It is mentioned above that estrogen played an important role in modulating affection and cognition in postmenopausal women, while, SSRIs also improve affective and cognitive disorder in late-life women. Thanks to the recent findings on the interaction between SSRIs and estrogen system on animal studies, such as rats (Taylor et al., 2004) and aquatic animals (Foran et al., 2004). Thus, we hypothesis that estrogen system may be one of mechanism of SSRIs involved in improving affection and cognition in postmenopausal women.

In the present study, we aimed to 1) clarify a possible relationship between Paroxetine which is one of SSRIs with the highest activity, and serum estrogen levels in a group of postmenopausal women with mood disorder undergoing treatment with Paroxetine for 6 months, 2) to evaluate the long-term modifications in cognition function as well as anxiety and depressive symptoms during treatment using Hamilton Anxiety Rating Scale-14 items (HAM-A), the Chinese version of the 17-item Hamilton Depression Rating Scale (HAM-D), Montreal 
cognitive assessment (MoCA-CV).

\section{Materials and Methods}

\subsection{Participants}

A total of 88 postmenopausal women with anxiety and depression were enrolled in the study from 2011 to 2012, including 6 patients lost to follow up, and 82 patients completed all sessions. All subjects had experienced their last menstrual period $\geq 12$ months previously, therefore, they were postmenopausal according to the Stages of Reproductive Aging Workshop criteria (Soules et al., 2001). Moreover, they all met the standard anxiety and depression diagnosis in the ICD-10 (Cooper, 1989). None of them had taken psychoactive drugs or hormonal therapies for at least 6 months before the beginning of the protocol; and they had no mood or behavior disease before the onset of the menopausal transition. Subjects were randomized into two groups: experiment group intervened by Paroxetine (E-group, 44 cases) and control group treated with oryzanol (C-group, 38 cases). This study was approved by the institutional review board of the Third Affiliated Hospital of Guangzhou Medical College (Guangzhou, China) and written informed consent was obtained from every participant.

Protocol: In pre-therapy and post-treatment, HAM-A, HAM-D and MoCA-CV assessments were administered to determine the status of anxiety, depression and cognition before blood sample collection measuring sex hormone.

Treatment: The treatment in E-group consisted of $10 \mathrm{mg}$ daily of Paroxetine (Glaxo Smith Kline) for the first week and the subsequent dose of $20 \mathrm{mg} /$ day (quaque nocte) for the rest of time of 6 months. While the C-group were treated with Oryzanol at $20 \mathrm{mg}$ three times per day for 6 months. $0.8 \mathrm{mg}$ of Alprozolam per day (quaque nocte) was prescribed for both of the groups in the first month and then the dose of Alprozolam was gradually reduced to stop using.

\subsection{Neuropsychological Scale Assessment}

Participants were selected for the anxiety-depression status using the standard anxiety and depression diagnoses in the ICD-10 (Cooper, 1989). The criteria include: 1) Score of HAM-A $\geq 14$ (Hamilton, 1959) and score of HAM-D $\geq 17$ (Zheng et al., 1988); 2) experience of major anxiety symptoms for at least 3 months or major depression symptoms for at least 2 weeks; and 3) decline in functioning at work and home. Of these patients, 39 had mixed anxiety were diagnosed with depression disease (MADD, ICD-10 code F41.2), 28 suffered from anxiety only (ICD-10 code F41.8) and 15 suffered from depression only (ICD-10 code F32.0). Cognitive function was evaluated by MoCA-CV (Wong et al., 2009; Zhang et al., 2008).

\subsection{Sex Hormones Evaluated by ELASA}

After overnight fasting, a blood sample was drawn from the cubital vein of each participant between 7:00 and 8:00 AM. Serum estradiol, follicle stimulating hormone, luteinizing hormone and progesterone levels were measured with ELISA kit, similarly to these described previously (Zhou et al., 2012; Welt et al., 2003). The assay sensitivity for E2, FSH and LH is $0.1 \mathrm{pg} / \mathrm{ml}, 0.1 \mathrm{mIU} / \mathrm{ml}$, and $0.1 \mathrm{mIU} / \mathrm{ml}$. The intra-assay coefficients of variation (CVs) for E2, FSH, LH, and were 6.5\%, 7.8\%, and 6.12\%. And the inter-assay CVs for E2, FSH, and LH were $6.5 \%, 7.8 \%$ and $6.12 \%$.

\subsection{Statistical Analysis}

Statistical analysis was performed by using the SPSS16.0 statistical software package (standard version 16.0; SPSS, Chicago, IL). All data were recorded as mean \pm standard deviation $(\mathrm{x} \pm \mathrm{s})$. The demographic data were analyzed using Student's t-tests. In addition, we used one-way analyses of variance (ANOVA) to analyze the differences between pre-therapy and post-therapy in the two groups. To control for potential confounders, we employed repeated-measures analysis of covariance (ANCOVA) and multivariate regression analysis (logistic). We tested the effects of each variable on E2 level, including the severity of anxious/depressive symptoms (HAM-A or HAM-D scores), MoCA-CV scores, or demographic variables. A $P$-value of less than 0.05 was considered to indicate statistically significant differences. 


\section{Results}

\subsection{Baseline Characteristics}

Baseline information of subjects was described in detail in Table 1. The age of patients range from 56 to 69 years old (mean, $61.89 \pm 6.32$ years), and there were no significant differences in demographic information, postmenopausal time, anxiety and depression course, HAM-A score, HAM-D score, MoCA-CV score and sex hormone levels before antidepressant treatment between the experiment group and the control group.

\subsection{Estrogen Decreased, LH and FSH Has No Change in Natural State}

To observe how the hypothalamic pituitary ovarian (HPO) axis work in natural state, we set the control group without intervened by Paroxetine to measure the sex hormones. In control group, estrogen declined to $37.54 \pm$ $7.61 \mathrm{pg} / \mathrm{ml}$ from $49.36 \pm 12.75 \mathrm{pg} / \mathrm{ml}$ (Figure 1(a)), and there was no significantly change in LH and FSH (Figures $1(b)$ and $1(c))$.

\subsection{Paroxetine Up-Regulated Estrogen, while Decreased LH and FSH}

Women receiving Paroxetine for 6 months showed a significant increase in serum estrogen values with respect to pretreatment and control group values $(57.24 \pm 14.65 \mathrm{pg} / \mathrm{ml}$ at post-therapy vs $48.45 \pm 10.25 \mathrm{pg} / \mathrm{ml}$ at the be-

Table 1. Demographics, neuropsychological test scores and hormone levels before treatment in the antidepressant treatment and control groups $(x \pm s)$.

\begin{tabular}{cccc}
\hline Groups & E-group (n=44) & C-group (n=38) & $P$ value \\
\hline Age (years) & $61.96 \pm 9.30$ & $61.43 \pm 8.41$ & 0.88 \\
Postmenopausal time (y) & $5.40 \pm 7.45$ & $5.23 \pm 6.80$ & 0.83 \\
Education (y) & $8.96 \pm 2.65$ & $9.51 \pm 3.47$ & 0.65 \\
Disease course (y) & $2.26 \pm 5.75$ & $2.18 \pm 4.12$ & 0.85 \\
HAM-A (scores) & $21.42 \pm 8.90$ & $20.75 \pm 7.32$ & 0.68 \\
HAM-D (scores) & $23.89 \pm 6.70$ & $24.37 \pm 8.14$ & 0.67 \\
MoCA-CA (scores) & $24.08 \pm 2.22$ & $23.94 \pm 2.68$ & 0.68 \\
E2 (pg/ml) & $48.45 \pm 10.25$ & $49.36 \pm 12.75$ & 0.69 \\
FSH (MIU/ml) & $50.56 \pm 16.78$ & $49.80 \pm 11.51$ & 0.71 \\
LH (MIU/ml) & $24.18 \pm 6.25$ & $23.54 \pm 6.58$ & 0.74 \\
\hline
\end{tabular}

E stands for experimental, and C stands for control.

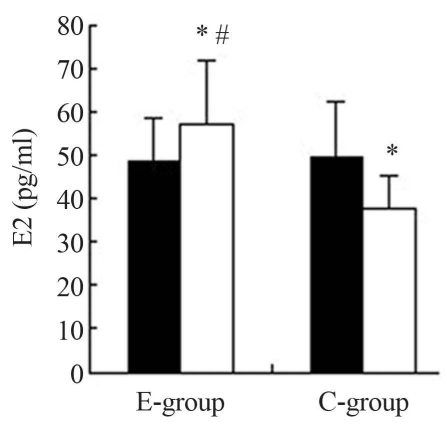

(a)

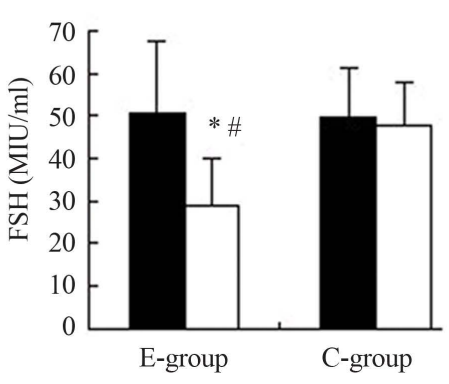

(b)

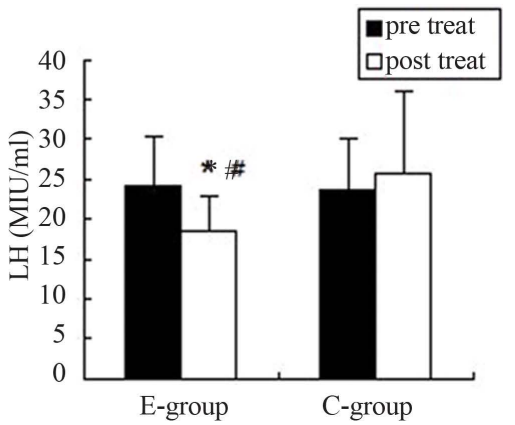

(c)

Figure 1. Paroxetine regulating on sex hormonal levels. The data are presented as mean \pm SD. ${ }^{*} P<0.005$ versus pretreatment in the two groups; ${ }^{\#} P<0.005$ versus post-treatment in control group. 
ginning of therapy or $37.54 \pm 7.61 \mathrm{pg} / \mathrm{ml}$ in control group, $P<0.05$ ) (Figure $1(\mathrm{a})$ ). And LH, FSH decreased significantly in the group treated by Paroxetine ( $\mathrm{LH}$ from $24.18 \pm 6.25 \mathrm{MIU} / \mathrm{ml}$ to $18.43 \pm 4.55 \mathrm{MIU} / \mathrm{ml}$, FSH from $50.56 \pm 16.78 \mathrm{MIU} / \mathrm{ml}$ to $28.90 \pm 11.34 \mathrm{MIU} / \mathrm{ml}$ ) (Figures 1 (b) and 1(c)).

\subsection{Paroxetine Relieved Anxiety and Depressive Symptom and Improve Cognitive Function}

Similarly to estrogen levels, HAM-A score from $21.42 \pm 8.90$ to $9.78 \pm 4.06$, HAM-D score from $23.89 \pm 6.70$ to $11.54 \pm 5.25$ (Figures 2(a) and 2(b)), declined significantly and MoCA-CV score raise to $26.92 \pm 1.92$ from $24.08 \pm 2.22$ by Paroxetine (Figure 2(c)). In control group, HAM-A score decreased, the HAM-D scores and MoCA-CV scores did not change (Figures 2(a), 2(b) and 2(c)).

\subsection{E2 Levels Was Significantly Associated with Scores of HAM-A, HAM-D and MoCA-CV at Pre-Treatment and Post-Treatment with Paroxetine}

To gain further insight whether the estrogen is probably one of the mechanism of SSRI improve emotional and cognitive function in post-menopausal women, we analyses the correlation between estrogen and neuropsychological scale scores. E2 levels were significantly correlated with MoCA-CV scores at pre- $(\mathrm{R}=0.52, P=0.012)$ and post-therapy of Paroxetine, $(\mathrm{R}=0.47, P=0.015)$, and negative correlated with HAM-D scores at pre $(\mathrm{R}=$ $-0.65, P=0.0001)$ and post-treatment $(\mathrm{R}=-0.37, P=0.036)$ and HARDS-14 scores at pre $(\mathrm{R}=-0.27, P=$ 0.043 ) and post-treatment $(\mathrm{R}=-0.24, P=0.047)$ (Table 2). The E2 levels was also associated with the rise in HAM-D scores $(\mathrm{R}=0.35, P=0.038)$ but this correlation did not happen in HARDS-14 scores $(\mathrm{R}=0.21, P=$ 0.052) (Table 2).

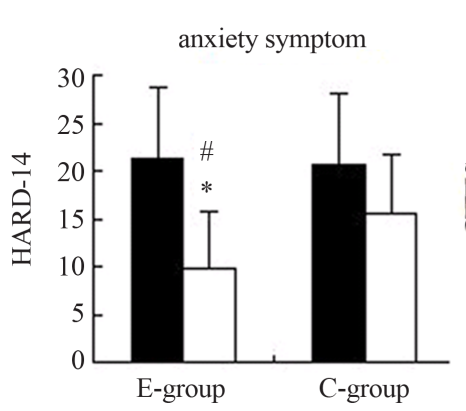

(a)

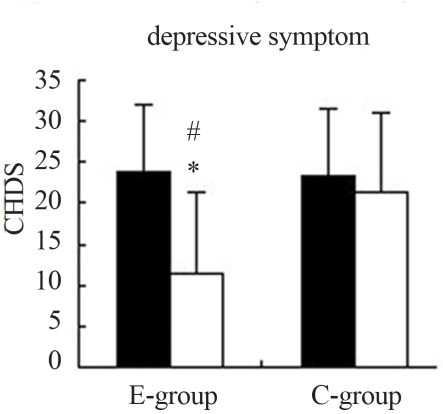

(b)

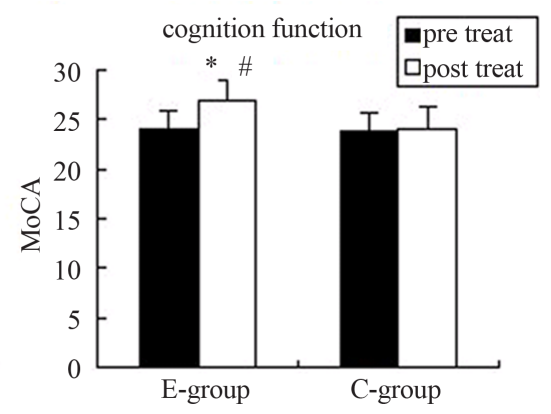

(c)

Figure 2. Paroxetine affecting clinical from the neuropsychological scale assessment. The data are presented as mean \pm SD. ${ }^{*} P<0.005$ versus pretreatment in the two groups; ${ }^{\#} P<0.005$ versus post-treatment in control group.

Table 2. Correlation between E2 levels and MoCA-CA scores, HAM-A-14/HAM-D and demographic information pre- and post-therapy in the antidepressant treatment group.

\begin{tabular}{ccccc}
\hline E-group & \multicolumn{2}{c}{ E2 $(\mathrm{pg} / \mathrm{ml})$ pre-therapy } & \multicolumn{2}{c}{ E2 $(\mathrm{pg} / \mathrm{ml})$ post-therapy } \\
Age & $\mathrm{R}=0.41$ & $P=0.028^{*}$ & $\mathrm{R}=0.37$ & $P=0.06$ \\
HAM-A-14 scores & $\mathrm{R}=-0.27$ & $P=0.043^{*}$ & $\mathrm{R}=-0.24$ & $P=0.047^{*}$ \\
HAM-D scores & $\mathrm{R}=-0.65$ & $P=0.0001^{*}$ & $\mathrm{R}=-0.37$ & $P=0.036^{*}$ \\
MoCA-CA scores & $\mathrm{R}=0.52$ & $P=0.047^{*}$ & $\mathrm{P}=0.012$ & $P=0.015^{*}$ \\
HAM-D scores & $\mathrm{R}=-0.65$ & $P=0.0001^{*}$ & $\mathrm{R}=-0.37$ & $P=0.036^{*}$ \\
Increased scores of HAM-A & $\backslash$ & & $\mathrm{R}=0.21$ & $P=0.052^{*}$ \\
Increased scores of HAM-D & $\backslash$ & $\mathrm{R}=0.35$ & $P=0.038^{*}$ \\
\hline
\end{tabular}

${ }^{*} P<0.05$. 


\section{Discussion}

E2 increased, LH, FSH decreased significantly comparing pre therapy with post treatment of Paroxetine. And in the control group, E2 level fell, FSH and LH were not significantly altered.

Aging has dramatic effects on the reproductive system in women. The estrogen levels in the control group suggest that serum level estrogen decreased with the aging and no change of LH, FSH in control group even when estrogen decreased indicated that a loss of ovarian function and subsequent the loss of negative feedback on the hypothalamus and pituitary at low level of estrogen in their natural state (Hall, 2007). But when estrogen increased by Paroxetine, the LH and FSH declined demonstrating preservation of the negative feedback in HPO axis, which is consistent with the results of Shaw's study in 2011 (Shaw, 2011), that LH and FSH also decrease in 22 postmenopausal women by administering a controlled intravenous steroid infusion that mimics estradiol (E2) and progesterone (P) levels across the follicular phase.

In the condition of estrogen going down with aging in the post-menopausal women, by treating with Paroxetine the estrogen did not decrease, instead, it increased which reversed the estrogen decreasing trend. It strongly suggests that Paroxetine is able to affect the serum level of estrogen in postmenopausal women.

How SSRIs regulate estrogen system? To our knowledge, there have not been previous human researches but several animal studies which have shown that serotonergic agent can modify estrogen titers and vice versa (Maswood et al., 1999; Raap et al., 2000). Rats injected with Fluoxetine revealed that concentrations of 0.5 - 5 $\mathrm{mg} / \mathrm{kg}$ may significantly alter circulating estrogen levels (Taylor et al., 2004). Moreover estradiol titers increased in Japanese medaka exposed to 0.1 and $0.5 \mathrm{mg} / \mathrm{l}$ Fluoxetine in water (Foran et al., 2004). The mechanism involved in the modulation of estradiol levels by Fluoxetine are unclear, but Rehavi et al. (2000) has speculated that in rats SSRIs may inhibit release of the luteinizing hormone (LH) which results in decreased ovarian release of estrogens in females. By contrast, in our experiment, estrogen increased and LH and FSH decreased after the treatment of Paroxetine, but we cannot exclude that the possibility of Paroxetine activating HPO axis to increase estrogen then followed by negative feedback in which LH and FSH went down. Moreover, in some cases SSRIs induce amenrrhea, hyperprolactinemia and galactorrhea, which have been also hypothesized that SSRIs may stimulate prolactin release directly via pre- or post-synaptic 5-HT receptors in the hypothalamus (Mondal et al., 2013), suggesting the existence of SSRIs effecting on hypothalamus.

Besides influencing HPO axis, attention can also be focused on data linking P450 and SSRI affecting estrogen synthesis and decomposition. For example, exposure to FLU has been shown to alter plasma estradiol levels and expression of the aromatase gene in the ovary of fish (Foran et al., 2004; Lister et al., 2009; Mennigen et al., 2010), the gen encoding cytochrome P450 enzyme aromatase in ovary catalyzing conversion of androgens into estrogens. Moreover, SSRIs have been also reported to influence a class of hepatic cytochrome P450 enzymes, responsible for metabolizing many endogenous and exogenous agents, including steroids (Brosen, 1995; Harvey et al., 1996). Thus, Paroxetine increases serum estrogen probably by modifying activity of cytochrome P450 enzymes in a manner that impacting the synthesis and decompose of estrogen.

Overall, SSRI's estrogenic effect has been confirmed, whose mechanism may be influencing HPO axis or estrogen's synthesis and composition. As we know, estrogen can regulate affective (Estrada-Camarena et al., 2010; Zanardi et al., 2007) and cognitive function (Zec et al., 2002; Tang et al., 1996) in postmenopausal women. However, there has been little information about estrogen involved in mechanism of SSRI improving affection and cognition in human. The current study is the first not only to show SSRI altering estrogen levels in human but also investigate the relations between the changes in estrogen and neuropsychological scale scores.

The Neuropsychological scale results showed a reduction in the score of HAM-A and HAM-D and an increase in MoCA-CV score in E-group comparing with C-group or pre-treatment. it indicates Paroxetine not only relieve anxiety and depressive symptoms but also improve cognitive function in post-menopausal women, which is consistent with previous reports (Paleacu et al., 2007; Savaskan et al., 2008). For example, Deanna M. Barch in 2012 found that both episodic memory and executive function demonstrated significant improvement among 166 adults with late-life depression during treatment with sertraline for 12 weeks (Barch et al., 2012).

Moreover, our results revealed that E2 levels were strongly correlated with HARDS-14 scores, HAM-D scores and MoCA-CV scores, which is also supported by previous evidence of a significant role of E2 on emotional disorder and cognitive function (Pae et al., 2008; Pan, 2010). Thus, this findings support our hypothesis that SSRI' altering estrogen levels may be one of mechanism in improve mood and cognitive disorder in the post-menopausal women. 
Why SSRIs increasing estrogen can modulate our emotion and cognition? To answer this question, BDNF has to be firstly mentioned. The critical neurotrophin regulates many neuronal aspects including cell differentiation, cell survival, neurotransmission, and synaptic plasticity in the central nervous system (Numakawa et al., 2010), which may be involved in the pathophysiology of Alzheimer's disease and mental disorders (Numakawa et al., 2010). There is close relationship between BDNF and estrogen or SSRIs. On one hand, It was demonstrated that E2 action on calcineurin may, therefore, contribute to regulate the cAMP response element binding protein (CREB) signaling through which E2 increases the expression of BDNF that may underlie some of the effects of E2 on affective and cognitive function (Zhou et al., 2005). On the other, SSRIs indirectly up-regulate the CREB and BDNF which contribute to neural protection (Vinet et al., 2004). Moreover, Paroxetine increased plasm BDNF in post-menopausal women with major depression (Cubeddu et al., 2010) or climacteric symptoms (Yasui-Furukori et al., 2011). Thus, it suggests that the possibility that CREB-BDNF signaling is the common pathway for the effects of estrogen and SSRIs on brain function, such as modulating emotion and cognition. And the information was also provided that BDNF may be the reason of SSRI increasing estrogen to improve emotional and cognitive function.

\section{Conclusion}

As far as we know, the current study is the first one not only to evaluate the correlation between Paroxetine and estrogen in postmenopausal women, but also finding that the altered estrogen levels are significantly related to emotional and cognitive function. Since this is a preliminary study, further studies are needed to determine the extent of the relevance of the data obtained. For one hand, more researches should be conducted to investigate the concrete mechanism of Paroxetine increasing estrogen levels, via HPO axis or P450? (Our group has started to do). For the other hand, in fact, it would be very interesting to measure the serum BDNF in this study. If we had known the correlation between serum BDNF and estrogen by Paroxetine in this study, it would be more determined that BDNF may be the reason that altered estrogen by Paroxetine improves affective and cognitive function. Thus, studies investigating the effects of SSRIs altering estrogen on CREB-BDNF signaling are warranted.

\section{Acknowledgements}

This study was supported by a research grant from the Science Technology Planning Project (NO. 2011 B060300027) of Guangdong Province, China.

\section{Conflict of Interest}

The authors declare no conflict of interest.

\section{References}

Barch, D. M., D’Angelo, G., Pieper, C. et al. (2012) Cognitive Improvement Following Treatment in Late-Life Depression: Relationship to Vascular Risk and Age of Onset. American Journal of Geriatric Psychiatry, 20, 682-690. http://dx.doi.org/10.1097/JGP.0b013e318246b6cb

Brosen, K. (1995). Drug Interactions and the Cytochrome P450 System: The Role of Cytochrome P450 1A2. Clinical Pharmacokinetics, 29, 20-25. http://dx.doi.org/10.2165/00003088-199500291-00005

Colenda, C. C., Legault, C., Rapp, S. R. et al. (2010). Psychiatric Disorders and Cognitive Dysfunction among Older, Postmenopausal Women: Results from the Women’s Health Initiative Memory Study. American Journal of Geriatric Psychiatry, 18, 177-186. http://dx.doi.org/10.1097/JGP.0b013e3181c65864

Cooper, J. E. (1989). An Overview of the Prospective ICD-10 Classification of Mental Disorders. The British Journal of Psychiatry. Supplement, 4, 21-23.

Cubeddu, A., Giannini, A., \& Bucci, F. et al. (2010). Paroxetine Increases Brain-Derived Neurotrophic Factor in Postmenopausal Women. Menopause: The Journal of The North American Menopause Society, 17, 338-343. http://dx.doi.org/10.1097/gme.0b013e3181c29e44

Cubeddu, A., Giannini, A., Bucci, F. et al. (2010). Paroxetine Increases Brain-Derived Neurotrophic Factor in Postmenopausal Women. Menopause, 17, 338-343. http://dx.doi.org/10.1097/gme.0b013e3181c29e44

Estrada-Camarena, E., Lopez-Rubalcava, C., \& Vega-Rivera, N. (2010). Antidepressant Effects of Estrogens: A Basic Ap- 
proximation. Behavioural Pharmacology, 21, 451-464. http://dx.doi.org/10.1097/FBP.0b013e32833db7e9

Fales, C. L., Barch, D. M., Rundle, M. M. et al. (2009). Antidepressant Treatment Normalizes Hypoactivity in Dorsolateral Prefrontal Cortex during Emotional Interference Processing in Major Depression. Journal of Affective Disorders, 112, 206-211. http://dx.doi.org/10.1016/j.jad.2008.04.027

Foran, C. M., Weston, J., Slattery, M., Brooks, B. W., \& Huggett, D. B. (2004). Reproductive Assessment of Japanese Medaka (Oryzias latipes) Following a Four-Week Fluoxetine (SSRI) Exposure. Archives of Environmental Contamination and Toxicology, 46, 511-517. http://dx.doi.org/10.1007/s00244-003-3042-5

Hall, J. E. (2007). Neuroendocrine Changes with Reproductive Aging in Women. Seminars in Reproductive Medicine, 25, 344-351. http://dx.doi.org/10.1055/s-2007-984740

Hamilton, M. (1959). The Assessment of Anxiety States by Rating. British Journal of Medical Psychology, 32, 50-55. http://dx.doi.org/10.1111/j.2044-8341.1959.tb00467.x

Harvey, A., \& Preskorn, S. (1996). Cytochrome P450 Enzymes: Interpretation of Their Interactions with Selective Serotonin Reuptake Inhibitors. Part II. Journal of Clinical Psychopharmacology, 16, 345-355.

http://dx.doi.org/10.1097/00004714-199610000-00002

Korczyn, A. D., \& Halperin, I. (2009). Depression and Dementia. Journal of the Neurological Sciences, 283, 139-142. http://dx.doi.org/10.1016/j.jns.2009.02.346

Kornstein, S. G., Schatzberg, A. F., Thase, M. E., Yonkers, K. A., McCullough, J. P., Keitner, G. I. et al. (2000). Gender Differences in Treatment Response to Sertraline versus Imipramine in Chronic Depression. American Journal of Psychiatry, 157, 1445-1452. http://dx.doi.org/10.1176/appi.ajp.157.9.1445

Lister, A., Regan, C., Van Zwol, J., \& Van Der Kraak, G. (2009). Inhibition of Egg Production in Zebrafish by Fluoxetine and Municipal Effluents: A Mechanistic Evaluation. Aquatic Toxicology, 95, 320-329. http://dx.doi.org/10.1016/j.aquatox.2009.04.011

Maswood, S., Truitt, W., Hotema, M., Caldarola-Pastuszka, M., \& Uphouse, L. (1999). Estrous Cycle Modulation of Extracellular Serotonin in Mediobasal Hypothalamus: Role of the Serotonin Transporter and Terminal Autoreceptors. Brain Research, 831, 146-154. http://dx.doi.org/10.1016/S0006-8993(99)01439-0

Mennigen, J. A., Lado, W. E., Zamora, J. M., Duarte-Guterman, P., Langlois, V. S., Metcalfe, C. D. et al. (2010). Waterborne Fluoxetine Disrupts the Reproductive Axis in Sexually Mature Male Goldfish, Carassius auratus. Aquatic Toxicology, 100, 354-364. http://dx.doi.org/10.1016/j.aquatox.2010.08.016

Million Women Study Collaborators (2003). Breast Cancer and Hormone-Replacement Therapy in the Million Women Study. Lancet, 362, 419-427. http://dx.doi.org/10.1016/S0140-6736(03)14065-2

Mondal, S., Saha, I., Das, S., Ganguly, A., Das, D., \& Tripathi, S. K. (2013). A New Logical Insight and Putative Mechanism behind Fluoxetine-Induced Amenorrhea, Hyperprolactinemia and Galactorrhea in a Case Series. Therapeutic Advances in Psychopharmacology, 3, 322-334. http://dx.doi.org/10.1177/2045125313490305

Numakawa, T., Suzuki, S., Kumamaru, E., Adachi, N., Richards, M., \& Kunugi, H. (2010). BDNF Function and Intracellular Signaling in Neurons. Histology and Histopathology, 25, 237-258.

Numakawa, T., Yokomaku, D., Richards, M., Hori, H., Adachi, N., \& Kunugi, H. (2010). Functional Interactions between Steroid Hormones and Neurotrophin BDNF. World Journal of Biological Chemistry, 1, 133-143. http://dx.doi.org/10.4331/wjbc.v1.i5.133

Pae, C. U., Mandelli, L., Han, C., Ham, B. J., Masand, P. S., Patkar, A. A. et al. (2008). Do Estradiol Levels Influence on the Cognitive Function during Antidepressant Treatments in Post-Menopausal Women with Major Depressive Disorder? A Comparison with Pre-Menopausal Women. Neuro Endocrinology Letters, 29, 500-506.

Paleacu, D., Shutzman, A., Giladi, N., Herman, T., Simon, E. S., \& Hausdorff, J. M. (2007). Effects of Pharmacological Therapy on Gait and Cognitive Function in Depressed Patients. Clinical Neuropharmacology, 30, 63-71. http://dx.doi.org/10.1097/01.wnf.0000240949.41691.95

Pan, M., Li, Z., Yeung, V., \& Xu, R. J. (2010). Dietary Supplementation of Soy Germ Phytoestrogens or Estradiol Improves Spatial Memory Performance and Increases Gene Expression of BDNF, TrkB Receptor and Synaptic Factors in Ovariectomized Rats. Nutrition \& Metabolism, 7, 75-85. http://dx.doi.org/10.1186/1743-7075-7-75

Potyk, D. (2005). Treatments for Alzheimer Disease. South Med J. http://dx.doi.org/10.1097/01.SMJ.0000166671.86815.C1

Raap, D. K., DonCarlos, L., Garcia, F., Muma, N. A., Wolf, W. A., Battaglia, G. et al. (2000). Estrogen Desensitizes 5-HT $1 \mathrm{~A}$ Receptors and Reduces Levels of $\mathrm{G}_{\mathrm{z}}, \mathrm{G}_{\mathrm{i} 1}$ and $\mathrm{G}_{\mathrm{i} 3}$ Proteins in the Hypothalamus. Neuropharmacology, 39, $1823-1832$. http://dx.doi.org/10.1016/S0028-3908(99)00264-6

Rehavi, M., Attali, G., Gil-Ad, I., \& Weizman, A. (2000). Suppression of Serum Gonadal Steroids in Rats by Chronic Treatment with Dopamine and Serotonin Reuptake Inhibitors. European Neuropsychopharmacology, 10, 145-150. http://dx.doi.org/10.1016/S0924-977X(00)00066-3 
Savaskan, E., Müller, S. E., Böhringer, A., Schulz, A., \& Schächinger, H. (2008). Antidepressive Therapy with Escitalopram Improves Mood, Cognitive Symptoms, and Identity Memory for Angry Faces in Elderly Depressed Patients. International Journal of Neuropsychopharmacology, 11, 381-388. http://dx.doi.org/10.1017/S1461145707007997

Shaw, N. D., Srouji, S. S., Histed, S. N., \& Hall, J. E. (2011). Differential Effects of Aging on Estrogen Negative and Positive Feedback. American Journal of Physiology-Endocrinology and Metabolism, 301, E351-E355. http://dx.doi.org/10.1152/ajpendo.00150.2011

Shumaker, S. A., Legault, C., Rapp, S. R., Thal, L., Wallace, R. B., Ockene, J. K. et al. (2003). Estrogen plus Progestin and the Incidence of Dementia and Mild Cognitive Impairment in Postmenopausal Women: The Women's Health Initiative Memory Study: A Randomized Controlled Trial. JAMA, 289, 2651-2662. http://dx.doi.org/10.1001/jama.289.20.2651

Soules, M. R., Sherman, S., Parrott, E., Rebar, R., Santoro, N., Utian, W., \& Woods, N. (2001). Executive Summary: Stages of Reproductive Aging Workshop (STRAW). Climacteric, 4, 267-272. http://dx.doi.org/10.1080/713605136

Tang, M. X., Jacobs, D., Stern, Y., Marder, K., Schofield, P., Gurland, B. et al. (1996). Effect of Oestrogen during Menopause on Risk and Age at Onset of Alzheimer's Disease. The Lancet, 348, 429-432. http://dx.doi.org/10.1016/S0140-6736(96)03356-9

Taylor, G. T., Farr, S., Klinga, K., \& Weiss, J. (2004). Chronic Fluoxetine Suppresses Circulating Estrogen and the Enhanced Spatial Learning of Estrogen-Treated Ovariectomized Rats. Psychoneuroendocrinology, 29, 1241-1249. http://dx.doi.org/10.1016/j.psyneuen.2004.03.001

Trivedi, M. H., Rush, A. J., Wisniewski, S. R. et al. (2006). Evaluation of Outcomes with Citalopram for Depression Using Measurement Based Care in STAR*D: Implications for Clinical Practice. American Journal of Psychiatry, 163, 28-40. http://dx.doi.org/10.1176/appi.ajp.163.1.28

Uher, R., Maier, W., Hauser, J., Marušič, A., Schmael, C., Mors, O. et al. (2009a). Differential Efficacy of Escitalopram and Nortriptyline on Dimensional Measures of Depression. British Journal of Psychiatry, 194, 252-259. http://dx.doi.org/10.1192/bjp.bp.108.057554

Vinet, J., Carra, S., Blom, J. M. C., Brunello, N., Barden, N., \& Tascedda, F. (2004). Chronic Treatment with Desipramine and Fluoxetine Modulate BDNF, CaMKK $\alpha$ and CaMKK $\beta$ mRNA Levels in the Hippocampus of Transgenic Mice Expressing Antisense RNA against the Glucocorticoid Receptor. Neuropharmacology, 47, 1062-1069. http://dx.doi.org/10.1016/j.neuropharm.2004.07.035

Welt, C. K., Pagan, Y. L., Smith, P. C., Rado, K. B., \& Hall, J. E. (2003). Control of Follicle-Stimulating Hormone by Estradiol and the Inhibins: Critical Role of Estradiol at the Hypothalamus during the Luteal-Follicular Transition. Journal of Clinical Endocrinology \& Metabolism, 88, 1766-1771. http://dx.doi.org/10.1210/jc.2002-021516

Wong, A., Xiong, Y. Y., Kwan, P. W., Chan, A. Y. Y., Lam, W. W. M., Wang, K. et al. (2009). The Validity, Reliability and Clinical Utility of the Hong Kong Montreal Cognitive Assessment (HK-MoCA-CV) in Patients with Cerebral Small Vessel Disease. Dementia and Geriatric Cognitive Disorders, 28, 81-87. http://dx.doi.org/10.1159/000232589

Writing Group for the WHI Investigators (2002). Risks and Benefits of Estrogen plus Progestin in Healthy Postmenopausal Women: Principal Results from the Women's Health Initiative Randomized Controlled Trial. JAMA, 288, 321-333. http://dx.doi.org/10.1001/jama.288.3.321

Wroolie, T. E., Williams, K. E., Keller, J., Zappert, L. N., Shelton, S. D., Kenna, H. A. et al. (2006). Mood and Neuropsychological Changes in Women with Midlife Depression Treated with Escitalopram. Journal of Clinical Psychopharmacology, 26, 361-366. http://dx.doi.org/10.1097/01.jcp.0000227699.26375.f8

Yasui-Furukori, N., Tsuchimine, S., Nakagami, T., Fujii, A., Sato, Y., Tomita, T. et al. (2011). Association between Plasma Paroxetine Concentration and Changes in Plasma Brain-Derived Neurotrophic Factor Levels in Patients with Major Depressive Disorder. Human Psychopharmacology, 26, 194-200.

Zanardi, R., Rossini, D., Magri, L., Malaguti, A., Colombo, C., \& Smeraldi, E. (2007). Response to SSRIs and Role of the Hormonal Therapy in Post-Menopausal Depression. European Neuropsychopharmacology, 17, 400-405.

http://dx.doi.org/10.1016/j.euroneuro.2006.11.001

Zec, R. F., \& Trivendi, M. A. (2002). The Effects of Estrogen Replacement Therapy on Neuropsychological Function in Postmenopausal Women with and without Dementia: A Critical and Theoretical Review. Neuropsychology Review, 12, 65-109. http://dx.doi.org/10.1023/A:1016880127635

Zhang, L. X., \& Liu, X. Q. (2008). The Preliminary Application of Montreal Cognitive Assessment of Chinese Version in the Older People in Guangzhou. Chinese Journal of Gerontology, 28, 1632-1634.

Zheng, Y. P., Zhao, J. P., Phillips, M., Liu, J. B., Cai, M. F., Sun, S. Q., \& Huang, M. F. (1988). Validity and Reliability of the Chinese Hamilton Depression Rating Scale. British Journal of Psychiatry, 152, 660-664. http://dx.doi.org/10.1192/bjp.152.5.660

Zhou, B., Sun, X., Zhang, M., Deng, Y. H., \& Hu, J. J. (2012). The Symptomatology of Climacteric Syndrome: Whether Associated with the Physical Factors Or Psychological Disorder in Perimenopausal/Postmen-Opausal Patients with An- 
xiety-Depression Disorder. Archives of Gynecology and Obstetrics, 285, 1345-1352. http://dx.doi.org/10.1007/s00404-011-2151-Z

Zhou, J., Zhang, H. B., Cohen, R. S., \& Pandey, S. C. (2005). Effects of Estrogen Treatment on Expression of Brain-Derived Neurotrophic Factor and cAMP Response Element-Binding Protein Expression and Phosphorylation in Rat Amygdalold and Hippocampal Structures. Neuroendocrinology, 81, 294-310. http://dx.doi.org/10.1159/000088448 


\author{
Abbreviations \\ ICD-10: International Classification of Diseases-10; \\ E2: Estradiol; \\ FSH: Follicle Stimulating Hormone; \\ LH: Luteinizing Hormone; \\ SSRIs: Selective Serotonin Reuptake Inhibitors; \\ HAM-A: Hamilton Anxiety Rating Scale-14 Items; \\ HAM-D: The 17-Item Hamilton Depression Rating Scale; \\ MoCA-CV: Montreal Cognitive Assessment; \\ HRT: Hormone Replacement Therapy; \\ BDNF: Brain Derived Neurotrophic Factor; \\ HPO: Hypothalamic Pituitary Ovarian.
}


Scientific Research Publishing (SCIRP) is one of the largest Open Access journal publishers. It is currently publishing more than 200 open access, online, peer-reviewed journals covering a wide range of academic disciplines. SCIRP serves the worldwide academic communities and contributes to the progress and application of science with its publication.

Other selected journals from SCIRP are listed as below. Submit your manuscript to us via either submit@scirp.org or Online Submission Portal.
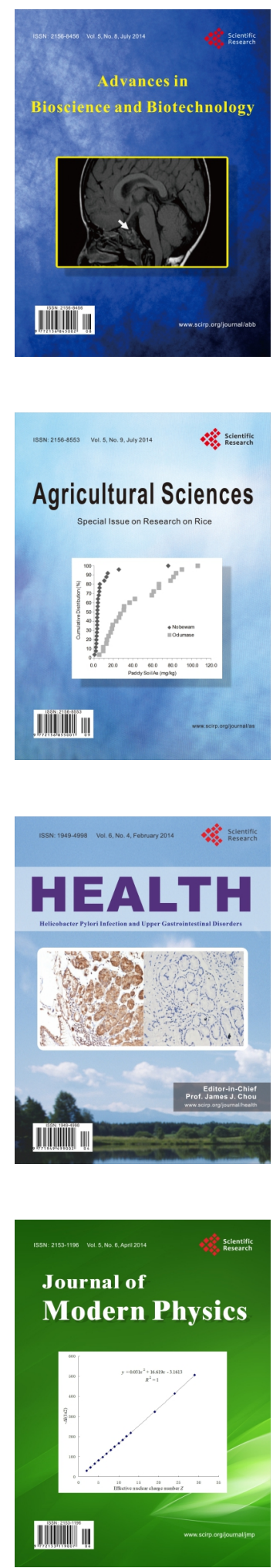
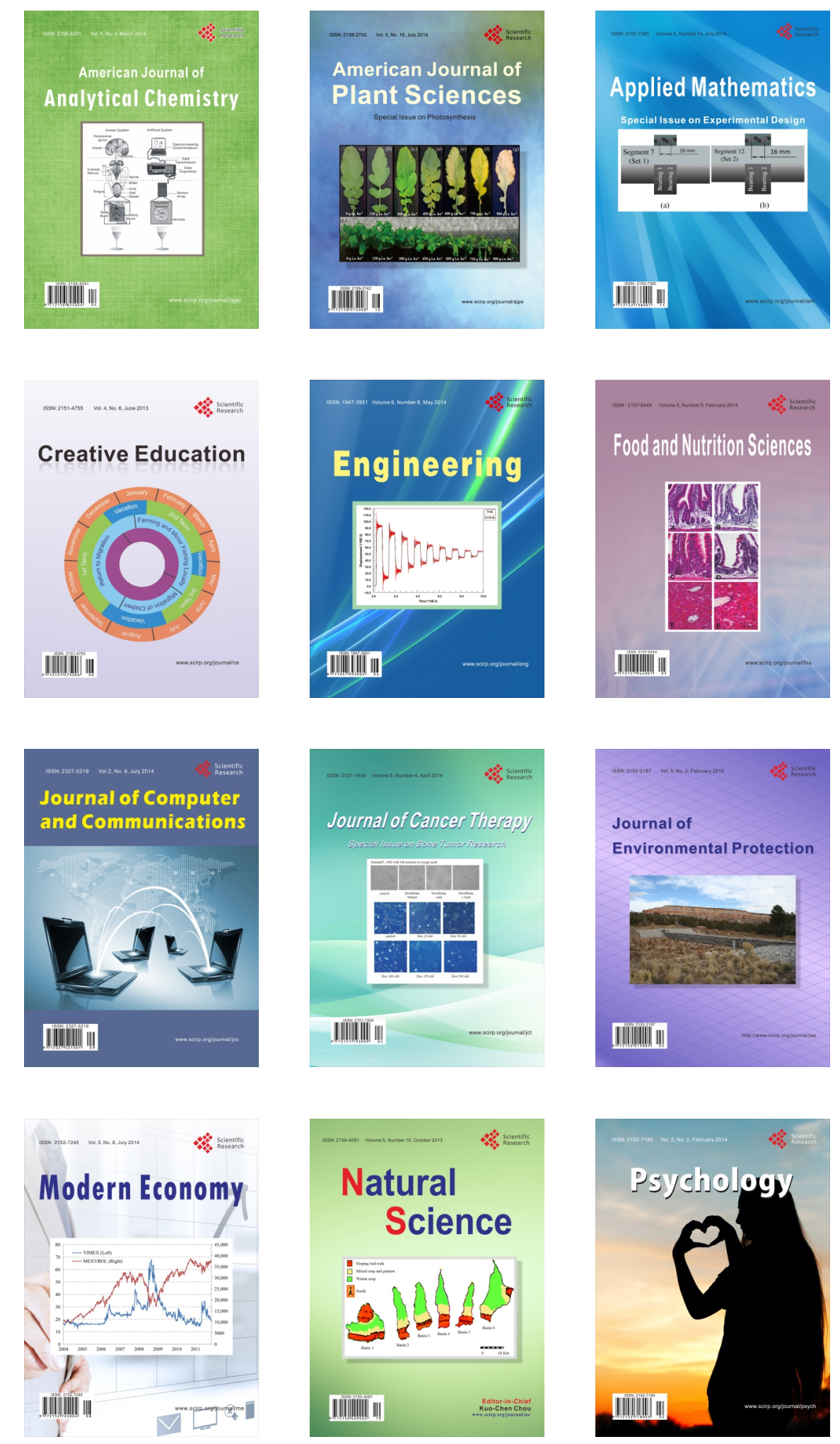